\title{
Effect of Roselle Extract in Expression of Matrix Metallo Proteinase - 8 (MMP-8) in Gingival Creviculer Fluid (GCF)
}

\author{
Lenni Indriani ${ }^{1}$, Mochammad Dharmautama ${ }^{2}$, Edy Machmud ${ }^{2}$, Muhammad Natsir Djide ${ }^{3}$, \\ Mochammad Hatta ${ }^{4}$ \\ ${ }^{1}$ Department of Dental Material, Faculty of Dentistry, Hasanuddin University, Makassar, Indonesia \\ ${ }^{2}$ Department of Prosthodontic, Faculty of Dentistry, Hasanuddin University, Makassar, Indonesia \\ ${ }^{3}$ Department of Microbiology and biotechnology, Faculty of Pharmacy, Hasanuddin University, Makassar, Indonesia \\ ${ }^{4}$ Molecular Biology and Immunology Laboratory, Departement of Microbiology. Faculty of Medicine, Hasanuddin University, Makassar, \\ Indonesia
}

\section{Email address:}

Lenni_601@yahoo.co.id (L. Indriani),mohdharmautama@gmail.com (M. Dharmautama), machmudedy@gmail.com (E. Machmud), natsirdj@yahoo.com (M. N. Djide), hattaram@indosat.net.id (M. Hatta)

\section{To cite this article:}

Lenni Indriani, Mochammad Dharmautama, Edy Machmud, Muhammad Natsir Djide, Mochammad Hatta. Effect of Roselle Extract in Expression of Matrix Metallo Proteinase - 8 (MMP-8) in Gingival Creviculer Fluid (GCF). American Journal of Clinical and Experimental Medicine. Vol. 4, No. 3, 2016, pp. 56-62. doi: 10.11648/j.ajcem.20160403.14

Received: March 24, 2016; Accepted: April 16, 2016; Published: May 11, 2016

\begin{abstract}
Background: This study is performed to determine the effect of roselle extract gel $10 \%$ toward the changing of MMP - 8 mRNA expression in Gingival Creviculer Fluid (GCF) in patient with gingivitis experience post acrylic crown insertion. Methods: This study is a pre and post test experimental research. Research subjects were 9 patients who experience gingivitis post acrylic crown insertion and divided in three groups (treatment with roselle gel, negative control, and positive control). GCF samples were taken with paper strips before and seven days after application of roselle extract gel $10 \%$. The change of MMP-8 mRNA expression is tested using Real Time-Polymerase Chain Reaction (RT-PCR) method. The results then statistically tested using paired T test to see the effect of rosella extract toward MMP- 8 activity. Result: The MMP - 8 mRNA expression in gingivitis post acrylic crown insertion crown in the experimental group is significantly decreased after application of roselle extract gel $10 \%$, which also seen in the positive control group, but no changes observed in the negative control group. Conclusions: Roselle extract gel $10 \%$ is proven to be effective in reducing the activity of MMP - 8 in GCF.
\end{abstract}

Keywords: Roselle Extract Gel, MMP - 8, Gingivitis, Acrylic Crown

\section{Introduction}

The use of the natural substances in the world of health tends to increase from year by year, which also occur in dentistry field. The main benefit of using natural ingredients in medication is minimal side effects which made them safer to use. One of the herbs that is widely used as beverage food and medicine is Hibiscus Sabdariffa (Roselle). This flower is known for anti-bacterial effect, containing anthocyanin pigments that act as antioxidants, and also has vitamins and minerals which are useful for the body. Research by Pacome et al found that petals of Roselle, such as anthocyanins, flavonoids and phenolic acid contribute to the antioxidative activity. This finding provide evidence that the petal extract of $H$. sabdariffa is a potential source of natural antioxidants, and this justify it application in folkloric medicines. [1]

The artificial crown is one alternative restoration that is made for aesthetic rehabilitation dental caries. The common materials used are acrylic, porcelain or combination of metal and porcelain that resemble a veil with forms and colors is adjusted to the natural tooth color. According to Oginni et al (2004), distribution and treatment frequency using artificial crown based on most frequent age is between 20-29 years old on vital $(24,7 \%)$ and on non vital teeth $(45,2 \%)$. [2]

The characteristic of restorative material such as surface roughness, can affect adhesion of bacterial coating which is caused by availability of surfaces for bacterial attachment 
and protection of bacteria colonization. [3, 4] The effects of crowns or Fixed Partial Dentures (FPDs) on gingival inflammation, probing depth, and bone loss were evaluated based on accuracy and reliability of measurement, and/or appropriateness of data analysis. Campbell and Knoernschild (2000) found that Crowns and FPDs increased the progressive gingival inflammation incident that occurred after restorations, especially if restorations is using intracrevicular finish line placement with impoverished marginal adaptation, or irregular surfaces. Clinically, both defective and acceptable restorations can play a role in gingival inflammation. [5]

Ababnaeh study in 2011 justifies the long held concept that restorations put under the gingival margin are harmful to gingival and periodontal well being. This study also proposes that in teeth with subgingival restorations, the increased loss of attachment started slowly and might be clinically discovered 1 to 3 years after the restorations procedure. Crowns, bridge abutments (especially acrylic and nonprecious metals) and Class II amalgam restorations appear to be associated with periodontal breakdown. [6]

Matrix metalloproteinase-8 (MMP-8) or collagenase-2 has been identified as the central biomarker in connective tissue injury that is caused by periodontitis [7] and is also known to have diagnostic value. Matrix metalloproteinase cause the increase of the blood barrier permeability by damaging extracellullar matrix, basal lamin and endothelial binding tissue, with the final result of acute inflammatory destruction. [8] Experiment conducted by Sorsa et al (2010), using immuno-fluorecentric assay technique and dentoanalyzen, detects MMP-8 in GCF samples. [9] Nowadays, 23 MMPs have been identified. MMP-1, MMP2, MMP-8 and MMP-9 and their relation to the gingival tissue inflamation and periodontal have become focus on several experiments.

Because of the effectiveness and safety of Roselle in inflammation process, in this experiment we applied Roselle gel toward post insertion gingivitis. We detected MMP-8 mRNA changes using Real Time PCR method, analyzed Roselle effect on expression of MMP-8 which is the gingivitis biomarker.

Before conducting this study, we acquired permission from Laboratory of Pharmaceutical Biotechnology Hasanuddin University, Laboratory of Microbiology Hasanuddin University, and Prosthetic Department of Dental Hospital Hasanuddin University, Indonesia. We also obtained ethical clearance from ethical committee Faculty of Medicine Hasanuddin University, Indonesia.

\section{Materials and Methods}

\subsection{Patient Selection}

The present study was conducted in the Department of Prosthodontic of Hasanuddin University, Makassar, South of Sulawesi, Indonesia. All patients were individually informed about the study, and informed consent form were signed.

\subsection{Groups}

A total of 9 (3 males and 6 females) individuals in the age range of 20-25 years who have gingivitis experience after insertiof of acrylic crown. They divided in three groups: Group I: treatment with roselle extract gel $10 \%$, group II: negative control (base gel), and group III: positive control (treatment with Povidon Iodine).

\subsection{The Extract of Roselle}

The identification of roselle petals is conducted to know the distinctiveness of crude drugs that are going to be used in the experiment. Four hundred grams of rosella petal was processed in the form of powder. Then 100 gram of simplisia powder was extracted by maceration using $1 \mathrm{~L}$ of ethanol which was placed in a glass jar for three days, filtered, and into the residue 1.125 L of ethanol was added, stirred and left inside a closed vessel for two days. The residue and sediment were separated from the filtrate using filter paper, the result of the filtrate I and II were mixed and decanted for two days and then were concentrated using a rotary evaporator to obtain a thick extract.

\subsection{Preparation of the Roselle Extract Gel}

The roselle gen contain Aquadest (mineral water), Methyl paraben, Hydroxyiethyl cellulose, Carboxyimethyl cellulose, Glycerin, Sodium cyclamate, and rosella extract. Eighty three $\mathrm{ml}$ of aquades was heated at $70-90^{\circ} \mathrm{C}$. Methyl paraben and cyclamates were added into aquades until they dissolve and then Hydroxyiethyl cellulose and Carboxyimethyl cellulose were added, then homogenized at the speed of $1000 \mathrm{rpm}$ until it a clear gel mass was formed. In this form, glycerin was added while still homogenized. Then, the homogeneous gel base was left until $30-40^{\circ} \mathrm{C}$. The last step was adding roselle extract into the gel while homogenized until it was mixed uniformly into the gel base.

\subsection{Procedure Gingival Crevicular Fluid Collection with Paper Strips}

The research materials were derived GCF of the acrylic crown users that were taken before and 7 days after application of roselle extract gel 10\%. GCF was obtained by isolating the gingival area that was using acrylic crowns. GCF was aspirated using filter paper or paper strip with dimension of $15 \mathrm{~mm} \times 3 \mathrm{~mm}$. The filter paper was left for 10 minutes at the gingival crevice in order to filter the GCF optimally. Once finished, the filter paper was inserted into a small tube that contain liquid L6.

\subsection{Nucleic acid Extraction (Boom et al, 1990)}

The gingival crevicular fluid from labial aspect is mixed with $500 \mathrm{ml}$ L6 lysis buffer liquid in the tube with cover. Then this mixture was centrifuged at $12.000 \mathrm{rpm}$ for 10 minutes. The concentrated sediment sample was homogenized for 30 minutes. Before adding the diatom suspension, the mixture of buffer L6 which already contains RNA from the extract was centrifuged for 2-3 minutes at 
$12.000 \mathrm{rpm}$, with the aim of RNA extracted settles at the bottom of the diatom tube. Twenty micro liter of diatom was added into the tube, the diatom suspense should always be rotated and stirred using a gyratory shaker, $100 \mathrm{rpm}$ for 10 minutes. L6 buffer and diatom mixtured was rotated again using eppendorf microcentrifuge at $12.000 \mathrm{rpm}$ for 15 seconds. Supernatant that was formed from each tube was separated using a suction tube which was made of a Pasteur pipette that was connected with a vacuum pump to prevent loss of diatoms in the suspense. Ten milliliters of the suspension was reserved.

Supernatant was washed two times using $1 \mathrm{ml}$ of L2 wash buffer. One milliliter of L2 wash buffer was added, rotated and centrifuged in $12.000 \mathrm{rpm}$ for 15 seconds, then the supernatant was discarded. The precipitate was washed again with $1 \mathrm{ml}$ of $70 \%$ ethanol twice, and then rotated and centrifuged at $12.000 \mathrm{rpm}$ for 15 seconds. The supernatant was discarded, the precipitate was washed again by $1 \mathrm{ml}$ acetone, rotated and centrifuged at $12.000 \mathrm{rpm}$ for 15 seconds. Then the supernatant was discarded again. Acetone remaining in the sediment was evaporated by opening the lid of the tube and heated in an oven at 50 $55^{\circ} \mathrm{C}$ for 10 minutes. After the sediment was dried, $60 \mathrm{~mL}$ of TE buffer elution was added, then rotated evenly so that the sediment and the suspension can be dissolved. Then, the tube was incubated in an oven at $56^{\circ} \mathrm{C}$ for 10 minutes. The mixture is centrifuged at $12.000 \mathrm{rpm}$ for 30 seconds. Forty to fifty microliters of supernatant was carefully obtained and put into a new tube. The result of the extraction were stored in $-80^{\circ} \mathrm{C}$.

\subsection{Detection of MMP - 8 Gene mRNA Expression}

The process of oligonucleotide specific gene primers for MMP 8 and glyceraldehyde 3 - phosphate dehydrogenase (GAPDH). The detection MMP 8 gene was performed using MMP sense primer 8, namely: GAT, GCT, ATC, ACC, ACA, CTC and CGT. Probe preparation: 283 bp. PCR Protocols: DNA replication is done by a cycle $94^{\circ} \mathrm{C}$ for 3 minutes, cycle is repeated 38 times in $94^{\circ} \mathrm{C}(30$ seconds). And antisense primer: ATT, TCA, GCT, GCT, GCG, TGG, A; PCR Protocol: $52^{\circ} \mathrm{C}(30$ seconds $), 72^{\circ} \mathrm{C}$ ( 40 seconds); $72^{\circ} \mathrm{C}$ ( 7 minutes $)$

To detect GADPH gene by using sense primer: TGGTATCGTGGAAGGACTCATGAC; probe preparation: 188 bp. PCR protocol: $94^{\circ} \mathrm{C}$ ( 3 minutes); 32 cycles $94^{\circ} \mathrm{C}(30$ seconds). And antisense primer: ATGCCAGTGAGCTTC CCGTTCAGC; PCR protocol: $56^{\circ} \mathrm{C}$ (40 seconds), $72^{\circ} \mathrm{C}(30$ seconds); $72^{\circ} \mathrm{C}$ ( 7 minutes).

Quantitative RT - PCR using Sybr qRT - PCR green master mix kit, one step. This protocol was optimized for MX 4000 instrument. Customized protocols was adjusted using the instrument by changing the dye dilution based on the instruction manual and followed the recommended factory instrument for RT - PCR cycle programme. The passive reference dye was put into reaction, diluted 1: 500. The solution that contains dye was kept away from light. Dilute 2 x SYBR Green qRT - PCR master mixed and stored on top of ice. Follow the master mix initial liquefaction, the unused portion was stored at $4^{\circ} \mathrm{C}$ with the note: avoid the repeated cycles of freeze-liquid.

The reaction of experiment was prepared by added the components below: Preparing reagent mixture for the reaction by using components below. The reagent mixture: we took the last volume $25 \mu$ (including RNA experiment) $12,5 \mu \mathrm{l}$ from 2 x SYBR green QRT-PCR master mix. $x \mu l$ from the first primer (best concentrate). Nuclease - free PCR - level H2 x $\mu 1$ the last concentrate (optimized concentrate).0,375 $\mu \mathrm{l}$ dye solution from the first step (optional). 1,0 $\mu 1$ from RT/RNAse the enzyme block mixture. The reaction was mixed gently to prevent bubbles formation (not rotated), then the mixture was distributed into experiment tube. We then added $\mathrm{x} \mu \mathrm{l}$ RNA experiments in each test tube. The reaction was mixed slowly to prevent bubbles formation (not rotated). The reactions were centrifuged in a short time. The reactions were put into instrument and the PCR programme as ready to be run.

\subsection{Statistical Analysis}

The data analysis was performed to investigate the change MMP- 8 mRNA from pretest to posttest for each group and we compared those change using paired t test $(\mathrm{P}<0,05)$.

\section{Results}

The analysis results of the change of expression of MMP 8 mRNA in GCF, in each group before gel application (pretest) (table 1).

Table 1. MMP - 8 before the application of the standard treatment of gingivitis post insertion acrylic crown.

\begin{tabular}{lllll}
\hline \multirow{2}{*}{ Variable } & \multicolumn{3}{l}{ Group } & \\
\cline { 3 - 5 } & & Treatment (Roselle extract Gel 10\%) & Negative control (Base Gel) & Positive control (Povidon Iodine) \\
\hline \multirow{2}{*}{$\begin{array}{l}\text { Expression of } \\
\text { mRNA MMP-8 }\end{array}$} & Mean & 11,142 & 8,757 & 11,914 \\
& SD & 0,578 & 3,040 & 3,306 \\
& $95 \% \mathrm{CI}$ & $9,71-12,58$ & $1,21-16,31$ & $3,70-29,13$ \\
\hline
\end{tabular}

Table 1 shows that the expression of MMP-8 mRNA in GCF pretest, among the three groups was not significant. The table above shows that all three groups could be considered homogeneous groups based on the expression of initial (pretest) MMP - 8 .
To evaluate the effect of the gel application of Roselle extract $10 \%$ toward the expression of MMP- 8 mRNA in GCF as the standard treatment of gingivitis post artificial crown insertion, we performed analysis using paired t test in each group (table 2). 
Table 2. The Comparison of the changes in the expression of mRNAof MMP - 8 GCF based on the group.

\begin{tabular}{|c|c|c|c|c|}
\hline \multirow{2}{*}{ Group } & \multicolumn{3}{|c|}{ Expression of $m R N A$ MMP-8 GCF } & \multirow{2}{*}{ p-value } \\
\hline & Pretest & Posttest & Changing & \\
\hline Roselle extract gel $10 \%$ & $11,142(0,578)$ & $8,190(1,139)$ & $2,952(1,154)$ & 0,047 \\
\hline Gel basis & $8,757(3,040)$ & $8,679(3,111)$ & $0,078(0,291)$ & 0,687 \\
\hline Povidon Iodine & $11,914(3,306)$ & $7,164(1,469)$ & $4,750(1,951)$ & 0,052 \\
\hline
\end{tabular}

Table 2 shows that the negative control group (base gel), showed no significant changes in the expression of MMP- 8 mRNA GCF; but in the treatment group (Roselle extract) there was a significant decrease as much as 2,952 (1,154), from 11.142 (0.578) to 8.190 (1.139); whereas in the positive control group (Povidon iodine) there was a decreased as much as 4.750 (1.951); from 11.914 (3.306) to 7.164 (1.469).

\section{Group}

$\begin{array}{cc}\text { Treatment (Rosella } & \text { Negative Control } \\ \text { gel) } & \text { (Base gel) }\end{array}$

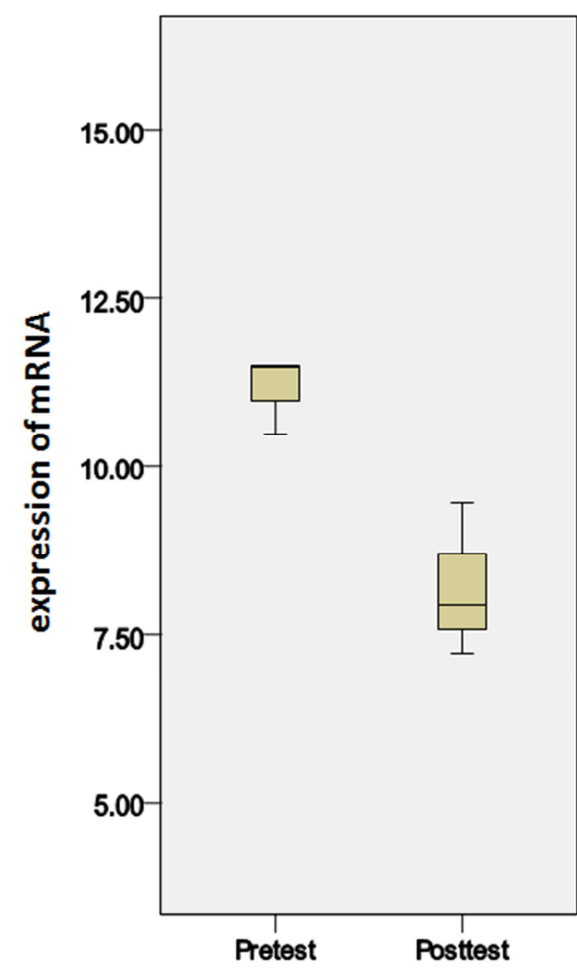

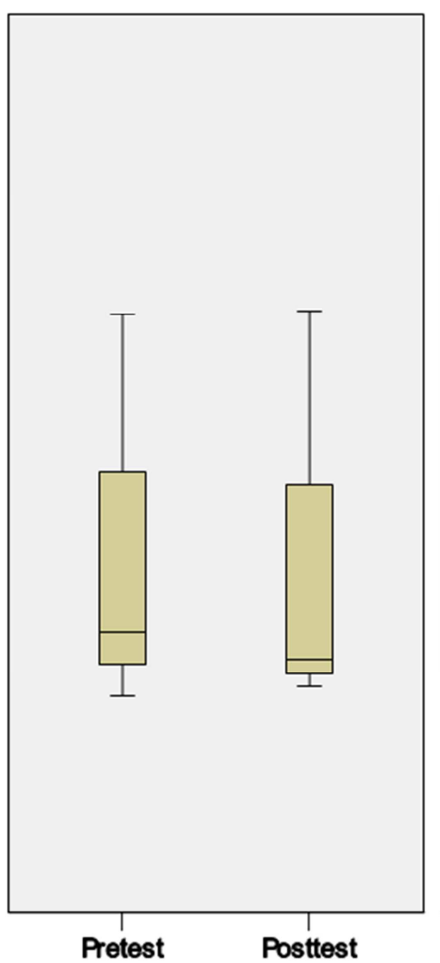

Time of Treatment

\section{Positive Control \\ (Povidon iodine)}

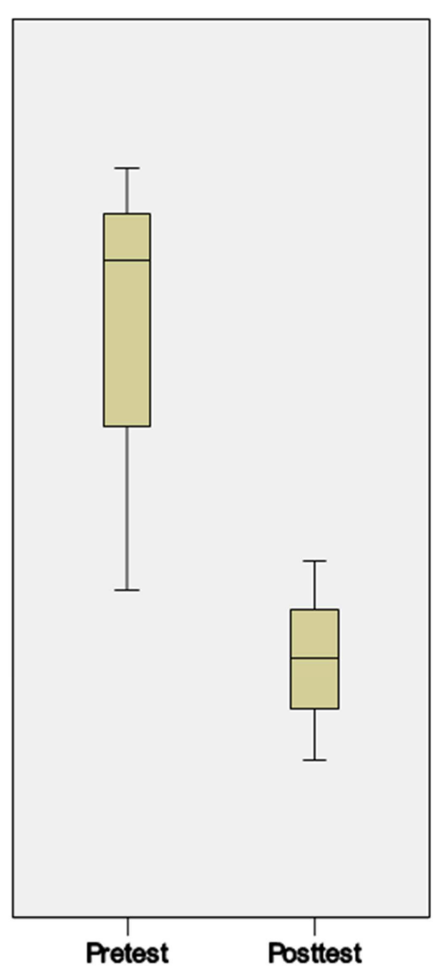

Figure 1. Plots Grafic box expression of MMP - 8 in GCF $m R N A$ pretest and posttest in all three groups.

From figure 1 we can see that the chart of the change of expression of MMP-8 mRNA in GCF, pretest to posttest in the experimental group showed a significant change, the positive control group do as well, but in the not in negative control group.

\section{Discussion}

The artificial crown is one alternative restoration that is made for aesthetic rehabilitation on dental caries. The common materials used are acrylic, porcelain or combination of metal and porcelain that resemble a veil with forms and colors is adjusted to the natural tooth color. The main preference in dental materials is those that are safe for the patient. Preferably, a material that is going to be applied in the patient's mouth should be toxic free, non- irritant and non carcinogenic. The contact of various material with the gingival and mucosal tissues will cause tissue response and therefore this response should be measured. The response can be classified as mild, moderate and severe. Mild response is characterized by mononuclear inflammation cells (mainly lymphocytes) in the epithelium and connective tissue. The 
moderate response is indicated by a number of mononuclear cells in the connective tissue and some neutrophils in the epithelium. Severe reactions will increase the infiltration of neutrophils and mononuclear and diminish epithelium tissue. Bacterial in plaque tissue plays an important role in producing inflammation of the gingival tissues. The second factor is the surface roughness of restorative materials, the open or overhanging on the edge, and over contouring or under contouring restoration. [11]

One previous research showed MMP- 8 gene expression changes after restoration installation which was performed by Peng (2011) who found that the level of MMP-8 at one month after crown placement in subgingival group was higher than the baseline $(\mathrm{P}<0.05)$ and continued to increase for three months after crown placement. The level of MMP-8 at the sixth months after crown placement in subgingival group was decreased, but was higher than the baseline. [12] In this research, we found that the expression of MMP -8 GCF early in all three groups, namely treatment group, negative control, and positive control (Povidon Iodine) did not differ significant (Table 1). In clinical appearance, we found a slight discoloration of the gingiva which was an inflammation sign of the gingival area at tooth that undergo restoration using acrylic crown. The increase of MMP - 8 occurred as the result of tissue damage in collagen bonds. In gingivitis, the matrix damage is caused by the activity of MMP which is produced by PMN leukocyte. In this study, the application of roselle extract gel 10\% showed changing in MMP - 8 gene expression that was found in GCF. MMP - 8 is one inflammation biomarker of the gingiva that can be detected in GCF.

Mantyla et al conducted a research on identifying and monitoring MMP - 8 in GCF in periodontitis subjects before and after treatment by a rapid chair -side method. The results indicated collagenase activity of MMP - 8 were higher in gingival inflammation and decreased with a good treatment on the gingiva. [13] Gingival inflamation or gingivitis is inflamation around gingival and It commonly occurs because of films of bacteria that accumulate on the teeth or artificial teeth. This result is in line with our research where the expression of MMP- 8 mRNA in GCF is decreased after application of rosella extract gel $10 \%$. In this research, we can found clinical appearence that there is inflammation in gingival around acrylic crown in group I, group II and so in group III before the treatment and Scoring of gingivitis all of groups were evaluated by Gingival Index by Silness and Loe (scoring $0=$ No inflammation, $1=$ Mild inflammation, slight change in color, slight edema, no bleeding on probing, $2=$ Moderate inflammation, moderate glazing, redness, bleeding on probing, $3=$ Severe inflammation, marked redness and hypertrophy, ulceration, tendency to spontaneous bleeding). The scoring of their gingivitis are score 1 (Mild inflammation, slight change in color, slight edema, no bleeding on probing). Seven days after treatment we evaluated condition of gingival. Group I, clinically showing gingival became normal and so group III, but in group II, there is no change (clinically still seen inflammation) (figure 2).
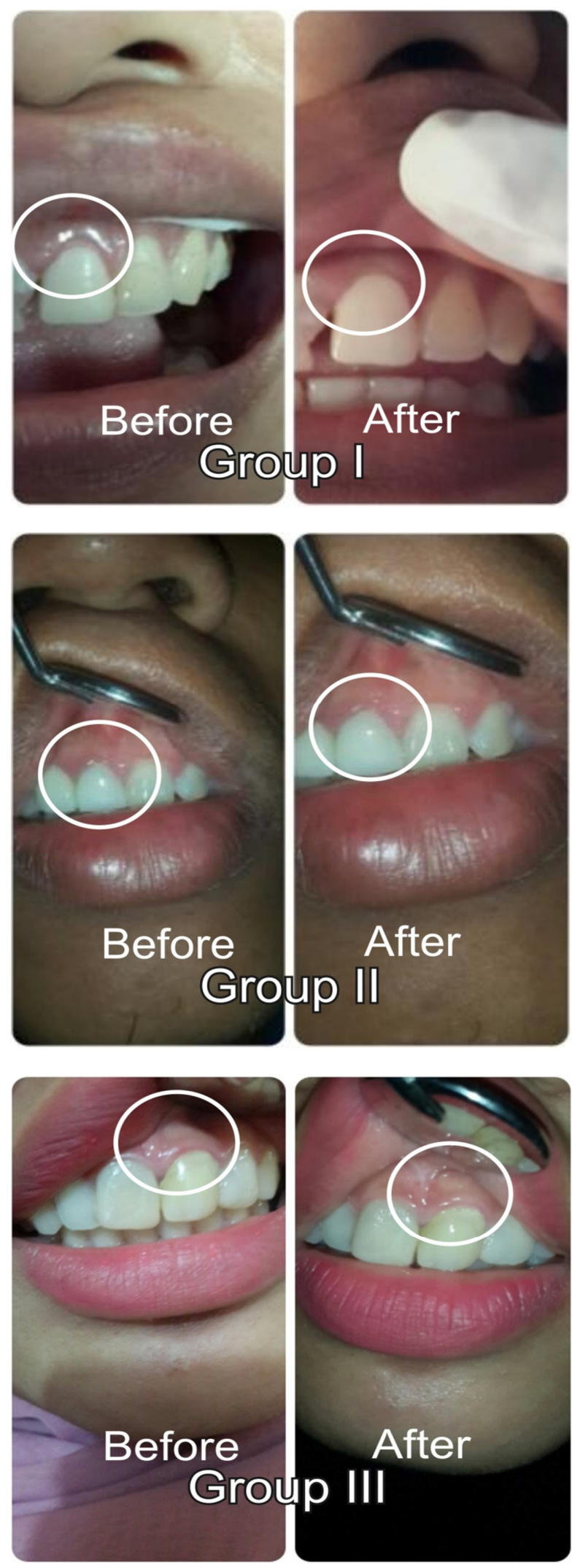

Figure 2. Clinical appearence before and after treatment in all groups.

The change in expression of MMP - 8 mRNA which was seen after application of roselle extract gel $10 \%$ is caused by the characteristics owned by Roselle which are anti inflammatory, antiviral, antimicrobial and antioxidant, where 
flavonoid can be found in all parts of $H$. sabdariffa or roselle. [14] Tannin that was found in this plant can diminish the bacteria proliferation by blocking the enzyme in microbial metabolism. Phenol contained in roselle have pharmacological properties, especially as anti -inflammatory, antiviral and cytotoxic. Research by Meraiyebu et al suggested that the methanolic extract of $H$. sabdariffa demonstrated therapeutic outcomes that were only significant at high dose of treatment. The therapeutic effect of this extract will encourage its use in inflammation treatment. [15] The peripheral analgesic activity of the ethanolic extract of the calyx of $H$. sabdariffa opposed to acute inflammatory pain was significantly high in comparison to potent inhibitory activity of Diclofenac (25mg) [16] which can also be seen in this research, where we found that after application of rosella extract gel $10 \%$ for one week, gingivitis was decreased until almost reaching normal condition because inflammatory act of roselle.

Inhibitory effect of $H$. sabdarifa corroborate the antibacterial effects of Roselle extracts against the test pathogens. The values obtained showed that the highest activity was recorded against $E$. coli in ethanol extracts of $H$. sabdariffa juice extract. The anti-microbial activities demonstrated by the extract of Roselle justify some of the ethno-pharmacological claims about this plant in the treatment of diseases caused by some of the test pathogens such as diarrhoea, dysentery, oral and dental infections. [17] In antimicrobial testing that has been done in this study by using bacteria $P$. gingivalis and $S$. sanguis, and we found that inhibition zone of rosella extract looks more effective in inhibiting the development of $S$. sanguis.

In this study also used povidon iodine (positive control) as the ingredient that is often used in the treatment of gingivitis. In this study, we found that povidon iodine is also able to reduce MMP - 8 and the results are not much different from the rosella extract gel $10 \%$ (Table 2). However, povidon iodine is antiseptic chemicals that has side effects which can cause sensitivity, local erythema, pain, mucosal erosion, and major risks associated with thyroid function. Some findings about the side effects of povidon iodine was reported, but no serious danger happens.

Based on the box plot in Fig. 1. gingivitis was occurred in post insertion of acrylic artificial crown and the effectiveness of roselle extract gel $10 \%$ has been proven can reduce the activity of MMP - 8 in GCF.

\section{Conclusion}

Evaluation of the effectiveness of roselle extract gel $10 \%$ using RT PCR method showed significant change in expression of MMP-8 mRNA, and this bring us to conclusion that there is a relationship between effectiveness of roselle extract gel $10 \%$ and changes in the expression of MMP 8 mRNA in GCF after application of the gel Roselle extract $10 \%$ in inflammation areas of the gingiva post acrylic crown insertion.

\section{Abbreviation}

FPDs: Fixed Partial Denture

GCF: Gingival Creviculer Fluid

MMP: Matrix Metallo Proteinase

RT PCR: Real Time Polymerase Chain Reaction

\section{References}

[1] Pacome, O. A., Bernard, DJYH N., Sekou D., Joseph D. A., David, N. J., Mongomake, K., et al., Phytochemical and Antioxidant Activity of Roselle (Hibiscus Sabdariffa L.) Petal Extracts. Research Journal of Pharmaceutical, Biological and Chemical Sciences. 2013.

[2] Oginni, A. O., Olusile, A. O., Udoye, C. I., Distribution and types of artificial crowns and bridges prescrbed at a Nigerian teaching hospital. Nigerian Journal of Clinical Practice. 2004; June: 7 (1): 24-7.

[3] Auschill T. M., Arweilier N. B., Breex M, Reich E., Sculean A., Netuschil L. The effect of dental restorative materials on dental biofilm. Eur J Oral Sci. 2002; 110: 48-53.

[4] El Mowaf, O., Gingiva response to crown: 3 year report. JCDA. 2007; 73: 10.

[5] Knoernschild K. L., Campbell S. D. Periodontal tissue responses after insertion of artificial crowns and fixed partial dentures. J Prosthet Dent. 2000; Nov: 84; 5: 492-8.

[6] Ababnaeh K. T., Al-Omari M, Alawneh T. N., The effect of dental restoration type and material on periodontal health. Oral Health Prev Dent. 2011; 9 (4): 395-403.

[7] Sorsa T., Tjaderhane L., Konttinen Y. T., Lauhio A., Salo T., Lee H. M., Golub L. M., Brown D. L., Mantyla P. Matrix metalloproteinases: Contribution to pathogenesis, diagnosis and treatment of periodontal inflammation. Ann Med; 2006; 38 (5): 306-21.

[8] Rosenberg G. A., Matrix metalloproteinase and their multiple roles in neurodegenerative diseases. Lancet Neurol. 2009; 8: 205-16.

[9] Sorsa T., Hernandez M., Leppilahti., Netuschii L., Mantyla P. Detection of gingiva crevicular fluid MMP-8 levels with different laboratory and chair-shide method. Oral Dis. Jan. 2010; 16 (1): 39-45.

[10] Boom. R., Sol C. J. A., Salimans M. M. M, Jansen C. L., Wetheim-vanillen P. M. E., van der Noordaa J. Rapid and Sample Methode for Purification of Nucleid Acid. 1990; 28: 495-03.

[11] McCabe J. F., Walls A. W. G, Applied Dental Material, 9th ed. Blackwell Publishing. 2008: 30

[12] Peng M. Y., Zhao L., Zhang Q., Hu C. H. The influence of two kinds of crown margin designs on MMP-8 and TIMP-1 levels in gingival crevicular fluid. Xi Bao Yu Fen Zi Mian Yi Xue Za Zhi. Article in Chinese. 2011 Dec; 27 (12): 1346-8.

[13] Mantyla P., Stenman M., Kinane D. F., Tikanoja S., Louto H., Solo T., et al. Gingiva Crevicular fluid collagenase-2 (MMP8 ) test stick for chair-side monitoring of periodontits. $J$. Periodontal Research. 2003; 38: 436-9. 
[14] Mungole A., Chaturvedi A. Hibiscus Sabdariffa L A Rich Source Of Secondary Metabolites. International Journal of Pharmaceutical Sciences Review and Research. 2011. January - February 6 (1); Article-018.

[15] Meraiyebu A. B, Olaniyan O. T, Eneze C., Anjorin Y. D., Dare J. B. Anti-inflammatory Activity of Methanolic Extract of Hibiscus sabdariffa on Carrageenan Induced Inflammation in Wistar Rat. International Journal of Pharmaceutical Science Invention. 2013; 2 (3): 22-4.
[16] Sarkar, M. d. R, Hossen S. M. M., Howlader, S. I., Rahman, Md. A,. Dey A., Anti-diarrheal, analgesic, and anti-microbial activities of the plant Lalmesta (Hibiscus Sabdarifah): a review. International Journal of Pharmacological and Life Sciences. 2012: November; 1 (3).

[17] Alaga T. O., Edema M. O., Atayese A. O., Bankole M. O. Phytochemical and in vitro anti-bacterial properties of Hibiscus sabdariffa L (Roselle) juice. Journal of Medical Plants Research.2014; 8 (6): 334-44. 